\title{
Osteoma of the cochlear promontory
}

Luis Manuel da Veiga Ferro Antunes', Pedro Correia Rodrigues ${ }^{2}$, Paulo Alexandre Martins ${ }^{3}$

1. Otorhinolaryngology Resident, Hospital de Santa Maria, Lisbon, Portugal Study carried out in the Department of Otorhinolaryngology, Hospital de Santa Maria, Lisbon, Portugal 2. Otorhinolaryngology Resident, Hospital de Santa Maria, Lisbon, Portugal 3. Senior Expert in Otorhinolaryngology, Hospital de Santa Maria, Lisbon, Portugal

KEYWORDS: Osteoma. Cochlea. Otolaryngology.

The authors describe the case of a 21-year-old patient with a history of recurrent otitis media and placement of transtympanic tubes during childhood. The patient consulted the otorhinolaryngology professional because of muffled hearing and otalgia in the right ear that had been occurring for 6 months. During the objective examination, the otoscopy revealed a rounded structure, visible through the transparency of the tympanic membrane (Figure 1). The audiometry test showed thresholds within the normal range. A computed tomography scan of the ear showed a nodular bone lesion, with bilateral implantation in the cochlear promontory (Figures 2 and 3 ), compatible with the diagnosis of osteoma of the

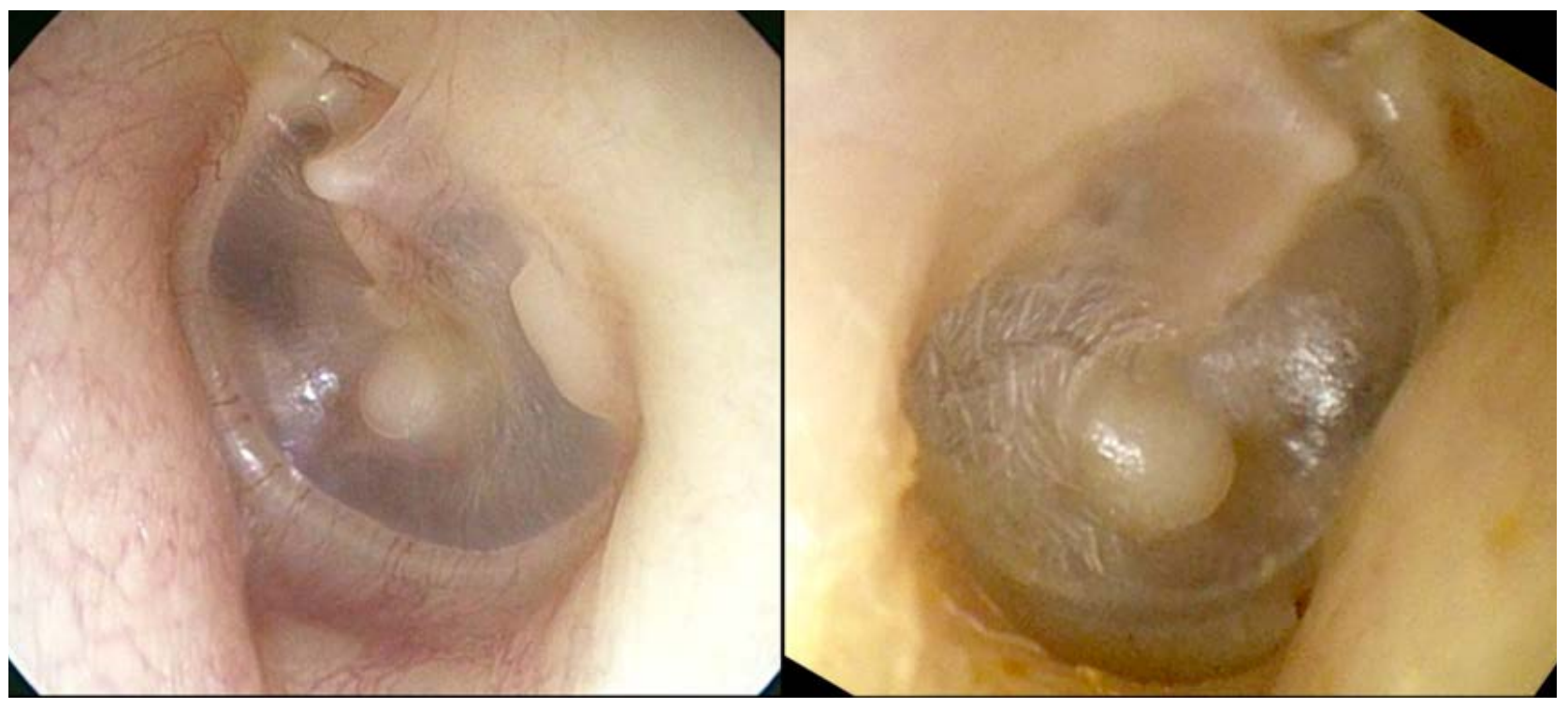

\section{FIGURE 1}

DATE OF SUBMISSION: 18-Jul-2017

DATE OF ACCEPTANCE: 23-Aug-2017

CORRESPONDING AUTHOR: Luis Antunes

Av Professor Egas Moniz, 1649-035

Lisboa- Portugal

E-mail: Luisvfantunes@gmail.com 


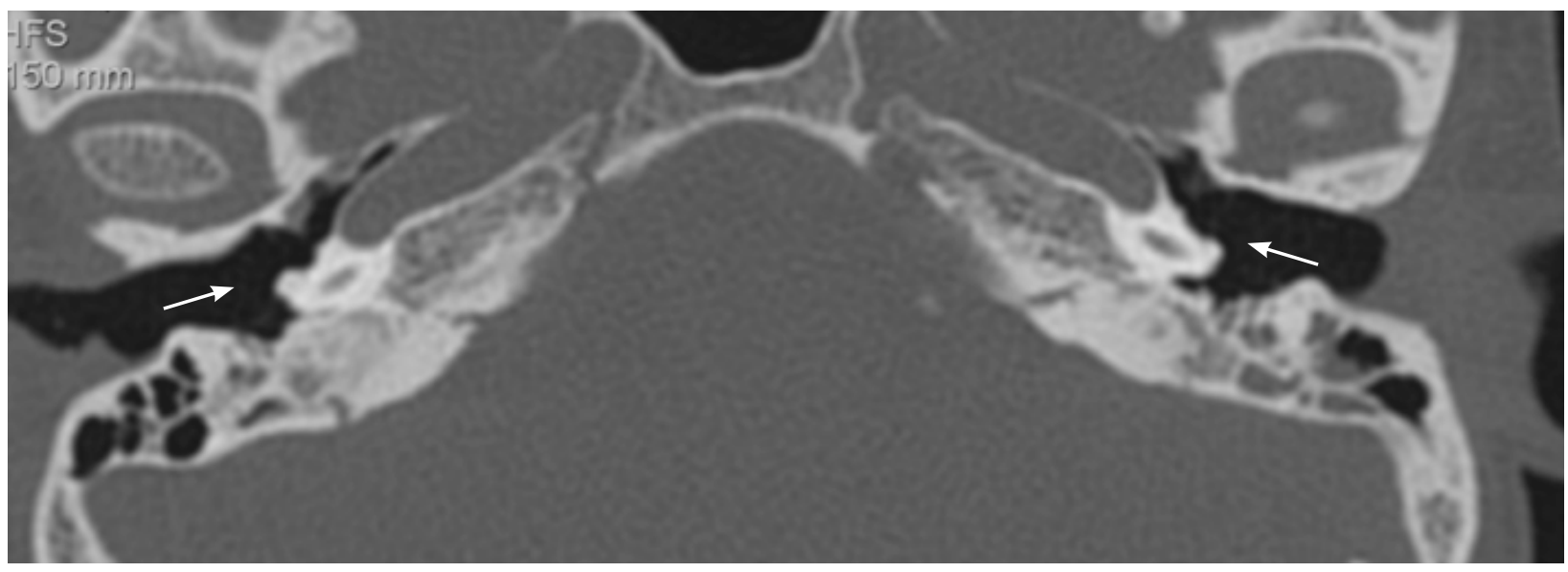

\section{FIGURE 2}

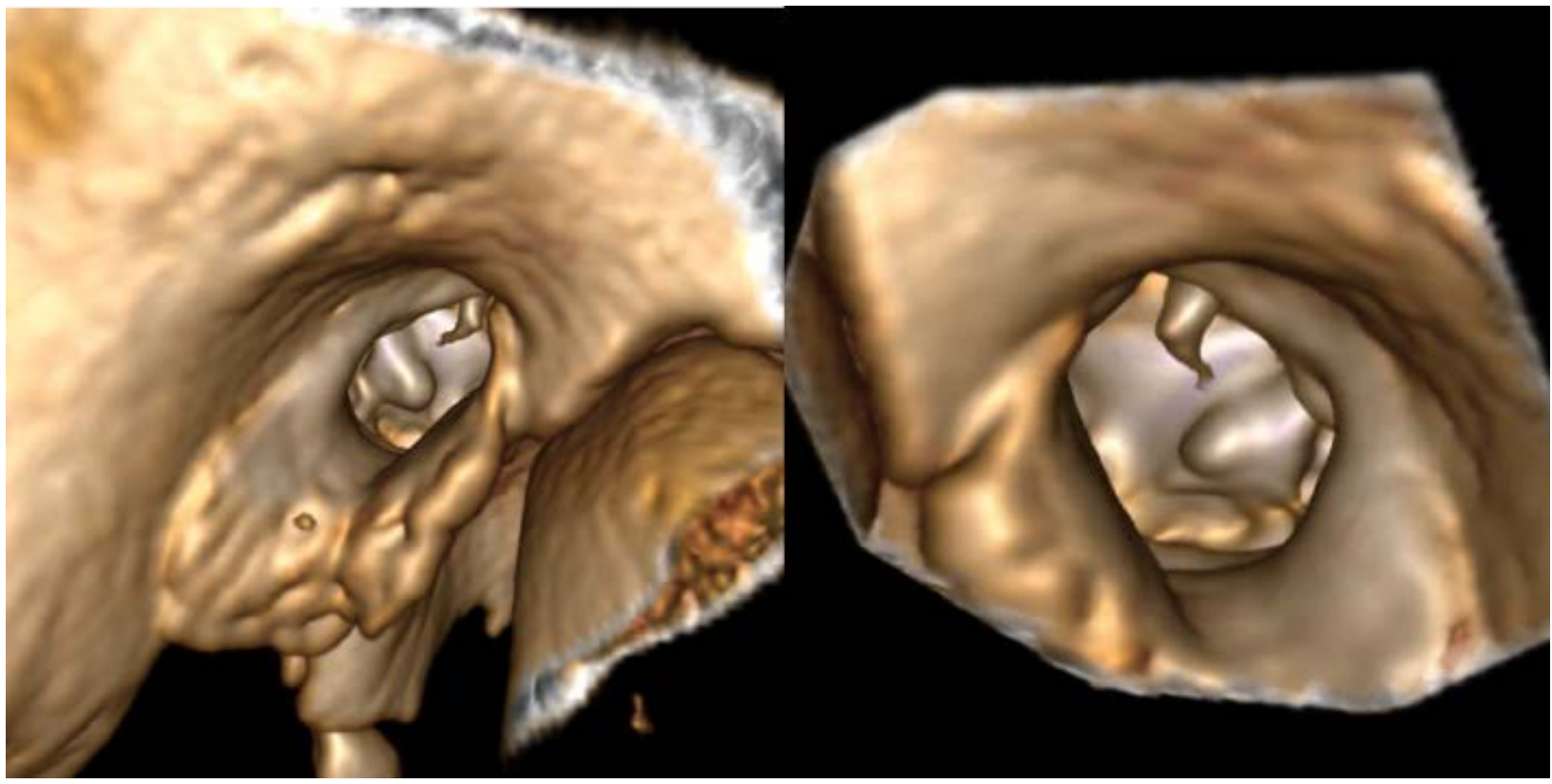

FIGURE 3

promontory. The patient has been under follow-up for 18 months, without further complaints.

The osteoma of the middle ear is a rare benign tumor. ${ }^{1}$ The most frequent initial symptom is the hypoacusis of transmission, ${ }^{2}$ however, in most cases it is asymptomatic. These are lesions of slow growth, and the conservative treatment ${ }^{3}$ is recommended with periodic monitoring in the absence of associated symptoms.
PALAVRAS-Chave: Osteoma. Cóclea. Otorrinolaringologia.

\section{REFERENCES}

1. Unal OF, Tosun F, Yetişer S, Dündar A. Osteoma of the middle ear. Int J Pediatr Otorhinolaryngol. 2000;52(2):193-5.

2. Silver FM, Orobello PW Jr, Mangal A, Pensak ML. Asymptomatic osteomas of the middle ear. Am J Otol. 1993;14(2):189-90.

3. Cremers CW. Osteoma of the middle ear. I Laryngol Otol. 1985;99(4):383-6. 